\title{
Classification of Synoptic Circulation Patterns for Fog in the Urumqi Airport
}

\author{
Nan Wang1, Lei Zhu'², Hongru Yang1, Lei Han'1 \\ ${ }^{1}$ Xinjiang Air Traffic Control Bureau Meteorological Center, Urumqi, China \\ ${ }^{2}$ Xinjiang Air Traffic Control Bureau Training Center, Urumqi, China \\ Email: wangnan1986yang@163.com
}

How to cite this paper: Wang, N., Zhu, L. Yang, H.R. and Han, L. (2017) Classification of Synoptic Circulation Patterns for Fog in the Urumqi Airport. Atmospheric and Climate Sciences, 7, 352-366. http://dx.doi.org/10.4236/acs.2017.73026

Received: June 20, 2017

Accepted: July 23, 2017

Published: July 26, 2017

Copyright (c) 2017 by authors and Scientific Research Publishing Inc. This work is licensed under the Creative Commons Attribution International License (CC BY 4.0).

http://creativecommons.org/licenses/by/4.0/

Open Access

\begin{abstract}
The purpose of this study is to investigate the Classification of Synoptic Circulation Patterns for Fog in the Urumqi Airport in Xinjiang, China. By using relevant climate statistical method, the hourly ground observation data and four times per day and NCEP/NCAR reanalysis data $\left(1^{\circ} \times 1^{\circ}\right)$ from 1985 to 2014 were analyzed. The results showed that: 1 ) The occurrence of fog significantly increased during 1985 and 2014; There are two stages of the airport fog in the 30 years, less-fog period (1985-2002) and more-fog period (2002-2014), the fog focused occurred in November to March of the following year, most in December and least in March; 2) Based on Lamb-Jenkinson method, the dominant types of fog in Urumqi Airport are C, E, SE, W, A types (Among them, A, C, E, W, SE are the circulation types. $\mathrm{C}$ is Cyclone, A is Anti-cyclone, $\mathrm{E}$ is East, $\mathrm{W}$ is West, $\mathrm{SE}$ is Southeast), and the international distribution of each type is also different; 3) The dominant types of persistence fog are A, C, E, SE types, A type appears in the afternoon to the nighttime, in the morning less frequent, on the other hand, C type is just the opposite; 4) Atmospheric circulation characteristics for persistence fog profile can be divided into four series: A, C, E, SE series, and climatic characteristics in different series are different.
\end{abstract}

\section{Keywords}

The Fog in Urumqi Airport, Climatic Variations, Atmospheric Circulation Classification

\section{Introduction}

According to the relevant definition in the Civil Aviation Weather, Part 1: Observations and Reports of the Civil Aviation Industry Standard of the People's Republic of China (MH/T 4016.1-2011) [1] issued by the Civil Aviation Administration of China (CAAC), fog is near ground water vapor condensation or 
condensate leaving the visibility reduced to $1000 \mathrm{~m}$ below the phenomenon. It is the biggest cause of aviation accidents, severe fog can lead to poor visibility, affecting the aircraft's normal taking-off and landing, increasing the aircraft's ice, bumps, etc., in the clouds [2]. A long-time continuing fog causes airport closures, flights canceled, resulting in a large number of passengers stranded, affecting the flight safety and normal operating order. In view of the causes and climatic characteristics of the foggy weather in Urumqi, the researchers have done a corresponding analysis from different perspectives. Researchers [3] [4] [5] analyzed the weather background, temperature and humidity characteristics, stratification conditions, surface wind and other meteorological conditions of the fog weather and indicated that the winter Urumqi fog is occurrence and maintenance under the joint action of a specific weather situation, a certain temperature and humidity condition and atmospheric vertical structure.

Aviation weather staffs have a lot of research on the airport fog. Chen [2] analyzed the daily, seasonal and inter-annual changes in the fog characteristics of the Capital Airport (Beijing, China). Li [6] pointed out the corresponding weather situation at different stages of fog respectively, classified the fog process, and analyzed the temporal characteristics, the background field characteristics and the physical characteristics such as air pressure and wind field before and after the appearance and disappearance of various fogs. In addition, Huang [7] analyzed the reasons on the Capital Airport advection fog formation, and put forward the forecast indicators. Dong [8] gave the summary on the characteristics of the daily and yearly variation characteristics of the fog in the Xianyang Airport (Shaanxi, China).

The Urumqi Airport is located in the fog high incidence area. The winter is the most important impact on flight safety and accuracy of the weather phenomenon. Wang [9] studied the characteristics of uneven distribution in the Urumqi Airport foggy season, but lacked research on circulation classification of fog in the Urumqi Airport. In the weather situation classification, it can be divided into subjective and objective methods. The subjective classification method is very intuitive and easy to explain its physical meaning, but this method mainly depends on experience, varies from person to person, and has obvious subjectivity. Based on the Lamb atmospheric circulation classification method [10], the Jenkinson method [11] (hereinafter referred to as the L-J method) is used to define the objective classification method by defining some objective criteria from qualitative classification. The Lamb-Jenkinson circulation type classification system is applied to obtain circulation information in China on daily basis. For that purpose, the NCEP daily mean sea-level pressure reanalysis data from 1 January 1948 to 31 December 2004 are used to derive daily six circulation indices and corresponding 27 circulation types for 16 sub-regions in China. The frequency of circulation types over different sub-regions and seasons is computed and described. Results show that Lamb-Jenkins on classification system is applicable for most of China, although in the west of China where might exist some errors in sea-level pressure due to high elevation. It automati- 
cally divides the circulation types to obtain the objective digital description for the local circulation, which overcomes the shortcomings of subjectivity, and has the advantages of easy calculation, objective result and clear meaning in synoptic meteorology. Its advantages are gradually recognized, so it is widely used in studies of climate change. From the perspective of synoptic climatology to study climate change, there is a potential value in climate prediction.

This study starts from the weather situation when the fog is formed, and analyzes the weather conditions of the Urumqi airport in fog. The L-J method is used to explore and analyze the possibility of weather classification, and provide the reference for improving the fog forecast in Urumqi. More accurate weather forecast and more timely measures are necessary to reduce the losses caused by foggy weather.

\section{Data and Methods}

\subsection{Data}

In this study, we use the visibility data of the Urumqi Airport from January 1985 to December 2014 , and the $1^{\circ} \times 1^{\circ}$ average sea level pressure reanalysis grid data of NCEP four times daily.

\subsection{Methods}

The Urumqi Diwopu International Airport (hereinafter referred to as "the airport") locates in the northwest suburb of Urumqi. The runway center coordinates of $87^{\circ} 28^{\prime} 28^{\prime \prime} \mathrm{E}, 43^{\circ} 54^{\prime} 23^{\prime \prime} \mathrm{N}$. In this study, we took the center $\left(16.5^{\circ} \mathrm{N}\right.$, $87.5^{\circ} \mathrm{E}$ ) of the area $32.5^{\circ} \mathrm{N}-52.5^{\circ} \mathrm{N}$ and $72.5^{\circ} \mathrm{N}-102.5^{\circ} \mathrm{E}$, and obtained 16 points from every 10 longitude and 5 latitude grid points (Figure 1), covering the Tianshan Mountains fog-prone areas. Then we did the circulation classification

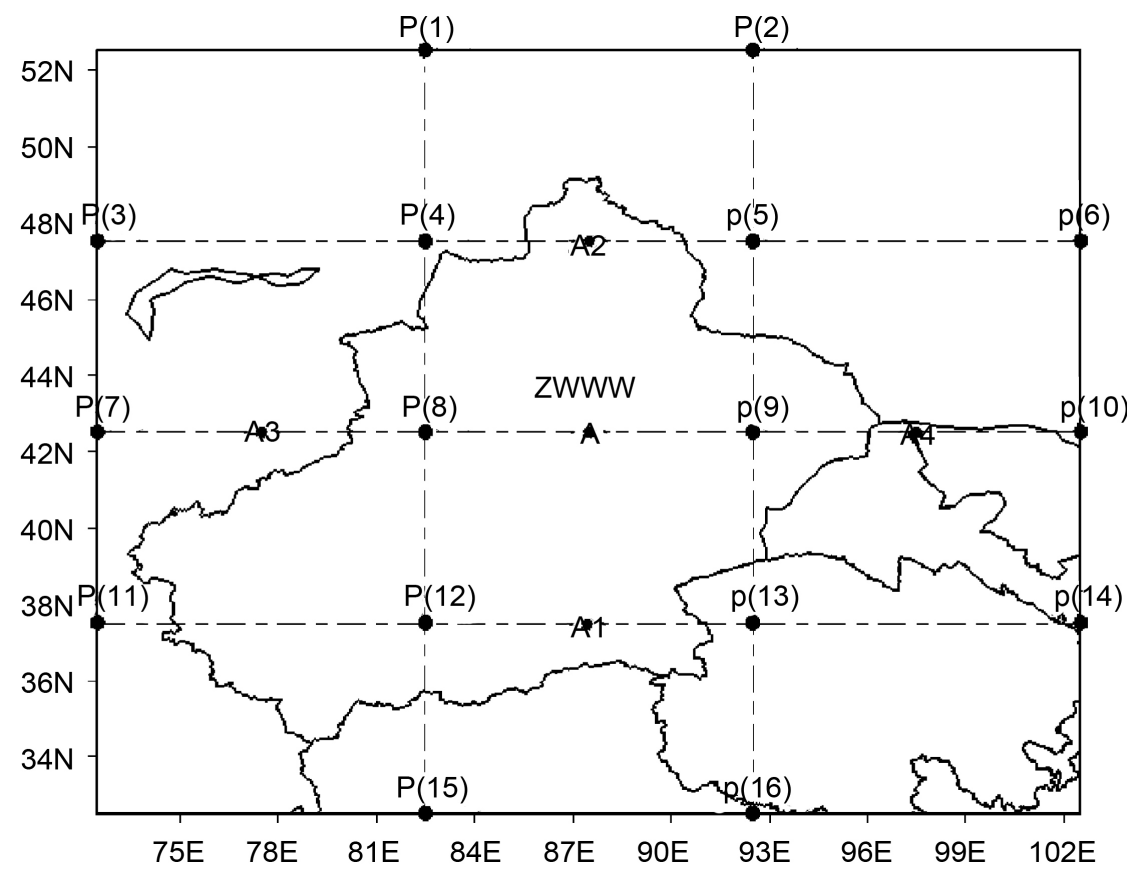

Figure 1. The 16 grid points in constructing the circulation climatology. 
by the range of daily mean sea-level pressure field and 6-hour sea level pressure field.

In the above area, the six circulant factors $u, v, V, \xi u, \xi_{V}$ and $\xi$ of the center point $\left(42.5^{\circ} \mathrm{N}, 87.5^{\circ} \mathrm{E}\right)$ are calculated from the monthly mean sea level pressure of 16 grid points by the difference formula. The specific formula is as follows:

$$
\begin{gathered}
u=0.5[P(12)+P(13)-P(4)-P(5)] \\
v=\frac{1}{\cos \alpha}[P(5)+2 P(9)+P(13)-P(4)-2 P(8)-P(12)] \\
V=\sqrt{u^{2}+v^{2}} \\
\xi_{u}=-\frac{\partial_{u}}{\partial_{y}}=\frac{\sin \alpha}{\sin \alpha_{1}} \frac{1}{2}[P(15)+P(16)-P(8)-P(9)] \\
-\frac{\sin \alpha}{\sin \alpha_{2}} \frac{1}{2}[P(15)+P(16)-P(8)-P(9)] \\
\xi_{v}=-\frac{\partial_{v}}{\partial_{x}}=\frac{1}{2 \cos ^{2} \alpha} \frac{1}{4}[P(6)+2 P(10)+P(14)-P(5)-2 P(9)-P(13) \\
+P(3)+2 P(7)+P(11)-P(4)-2 P(8)-P(12)] \\
\xi=\xi_{u}+\xi_{v}
\end{gathered}
$$

We take $u, v, V, \xi_{u}, \xi_{v}$ and $\xi$ in Equations (1)-(6) as the six circulation indexes to divide the circulation type.

In the above equation, $P(n)$ is the sea level pressure $(n=1,2, \cdots, 16)$ on the $n$th grid, which is the latitude value of the center point, A1 and A2 respectively. Small letters $u, v$ are the zonal and radial components of the ground wind, $\xi$ is the total shear vorticity, $\xi_{u}$ is the meridional gradient of $u, \xi_{v}$ is the zonal gradient of $\mathrm{V}$, and the units of the six circulation indexes are $\mathrm{hPa} / 10^{\circ}$.

From the Equations (1), (2) to calculate $u, v$, the direction of the geostrophic wind is determined by the following formula:

$$
\begin{cases}\alpha=\arctan (u / v) & V<0 \\ \alpha=\arctan (u / v)+180 & V>0\end{cases}
$$

According to the geostrophic wind speed, direction and vorticity value, the circulation is divided into three types: airflow type, rotary type and mixed type (Table 1). We define airflow type when $|\xi| \leq V$, which includes north $(\mathrm{N})$, northeast (NE), east (E), southeast (SE), south (S), southwest (SW), west (W) and northwest (NW); When $|\xi| \geq 2 V$, it is for the rotation of the circulation, including anti-cyclone (A) and cyclone (C); There is also a combination between the above two, that is, $V<|\xi|<2 V$, which is called the mixed circulation, that is, the combination of flat circulation and rotating circulation; If $|\xi|<6$ and $\mathrm{V}<6$, the circulation has not a exact characteristic, known as undefined, expressed as UD. This can define 27 different types of circulation.

$\mathrm{N}$ is North, NE is Northeast, E is East, SE is Southeast, S is South, SW is Southwest, W is West, NW is Northwest; $\mathrm{C}$ is Cyclone, $\mathrm{A}$ is Anti-cyclone; $\mathrm{CN}$ is Cyclone North, CNE is Cyclone Northeast, CE is Cyclone East, CSE is Cyclone 
Table 1. Lamb-Jenkinson circulation classification.

\begin{tabular}{|c|c|c|c|c|}
\hline Airflow type & \multicolumn{2}{|c|}{ Rotary type } & Mixed type & Undefined type \\
\hline$|\xi| \leq \mathrm{V}$ & \multicolumn{2}{|c|}{$|\xi| \geq 2 \mathrm{~V}$} & $\mathrm{~V}<|\xi|<2 \mathrm{~V}$ & $|\xi|<6$ and $V<6$ \\
\hline $\mathrm{N}$ & $\mathrm{CN}$ & AN & $\mathrm{C}$ & UD \\
\hline $\mathrm{NE}$ & $\mathrm{CNE}$ & ANE & A & \\
\hline $\mathrm{E}$ & $\mathrm{CE}$ & $\mathrm{AE}$ & & \\
\hline SE & CSE & ASE & & \\
\hline S & CS & AS & & \\
\hline SW & CSW & ASW & & \\
\hline $\mathrm{W}$ & $\mathrm{CW}$ & AW & & \\
\hline NW & CNW & ANW & & \\
\hline
\end{tabular}

Southeast, CS is Cyclone South, CSW is Cyclone Southwest, CW is Cyclone West, CNW is Cyclone Northwest; AN is Anti-cyclone North, ANE is Anti-cyclone Northeast, AE is Anti-cyclone East, ASE is Anti-cyclone Southeast, AS is Anti-cyclone South, ASW is Anti-cyclone Southwest, AW is Anti-cyclone West, ANW is Anti-cyclone Northwest.

\section{Results and Analysis}

\subsection{Inter-Monthly Distribution of the Urumqi Airport's Fog Accumulated Time}

For the Urumqi Airport, fog accumulated time was 13,225 hours during 1985 to 2014, and showed a clear upward trend (Figure 2). From the histogram, this upward trend is divided into two more obvious periods: before 2002, the cumulative occurrence of fog was very uniform, with an average of 293.5 hours/year; and the cumulative increase in fogging time after 2002 was rapid and averaged the value of 633.5 hours/year, for the high fog period. In addition, the airport fog generally began in November each year, December to next January the most. In early spring season fog began to decrease, and after mid-March rarely appeared. The cumulative fog of the month above accounted $99.3 \%$ for the year. In December, fog average annual cumulative time was 87.9 hours, the distance percentage of $76 \%$, followed by fog easy to appear in January, and March at least.

\subsection{Circulation Situation when Fog Occurs}

\subsubsection{Frequency of Circulation Type}

By using the method shown in Section 1.2 to divide the circulation types from January 1, 1985 to December 31, 2014, Figure 3 shows the frequencies of the circulation types of the Urumqi Airport in the above time range.

In addition, five circulation types, $\mathrm{E}, \mathrm{SE}, \mathrm{W}, \mathrm{A}$, and $\mathrm{C}$, in the proportion of each month are not the same. According to Table 2, the SE-type fog appeared more in December and January (two months for the most fogs), followed by February and November, less in March (month for the least fogs), that is, SE-type fog's inter-monthly distribution and whole fog accumulated time distribution are the same. 


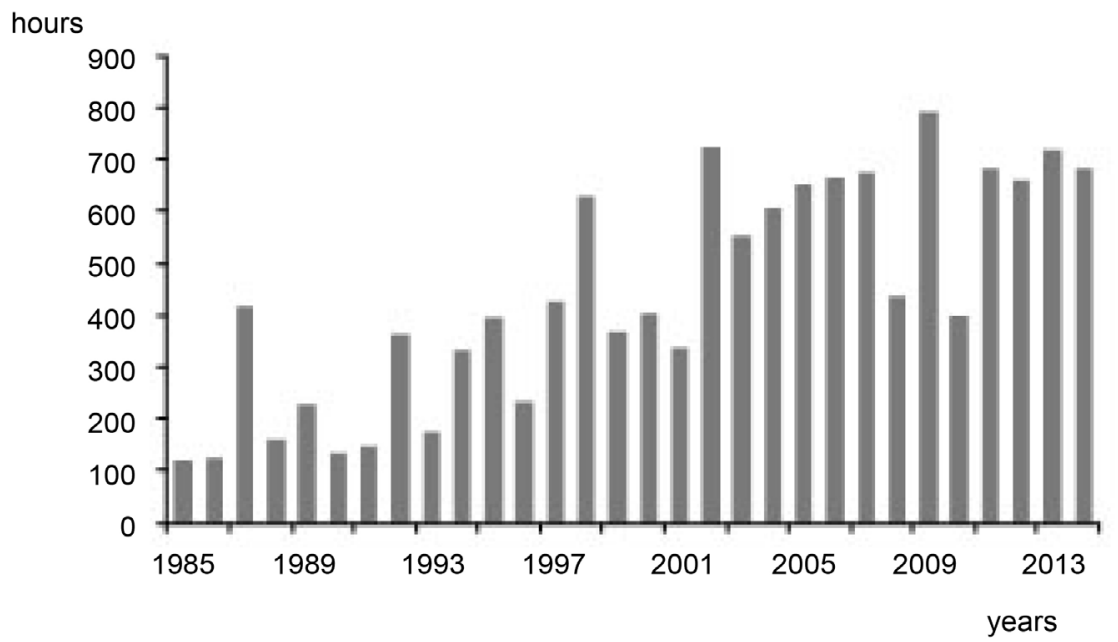

Figure 2. Trend of appearance time for fog in the Urumqi Airport during 1985 to 2014.

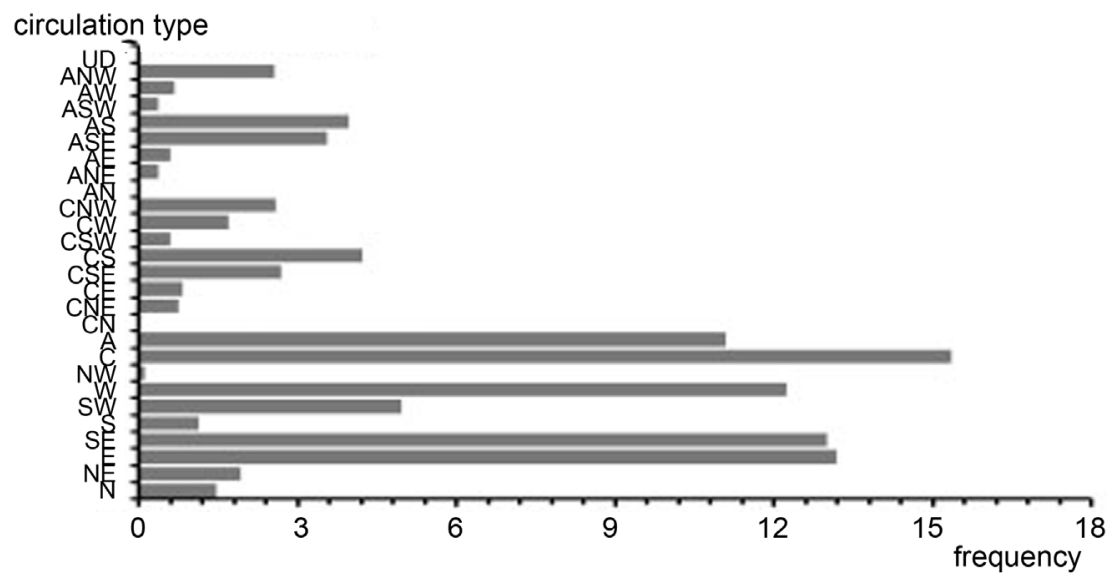

Figure 3. Frequency distribution of the circulation types during 1985 and 2014.

E-type fog distribution is more average; in addition to relatively few in November, the remaining four months difference is not big, and the largest is in February. C-type fog is the most uneven distribution of the five months, more in November, followed by March, however, foggy in December, January, February is relatively less. A type appears mainly in December and January. C-type is mainly in November, March, respectively, late autumn and winter.

\subsubsection{Persistent Fog Circulation Classification}

Persistent fog has a huge impact on the punctual and safe operation of the flight. As the data used in this study is a per-6-hour reanalysis data, in order to analyze the type characteristics of persistent fog, this study screens the fog weather process with duration of 12 hours or more. After quality control, we select a total of 95 persistent fog process in 1985-2014, which have a total of 312 times as a sample to study the persistent fog for the circulation classification. Persistent fog type distribution is more dispersed. There were only 4 persistent fog types, which were type A (14.6\%), type C (14.1\%), SE type (13.1\%) and E type (12.2\%), respectively. And the above four types in the distribution of time also have their 
Table 2. Monthly frequencies (\%) of the circulation types between 1985 and 2014.

\begin{tabular}{|c|c|c|c|c|c|}
\hline Type & Jan. & Feb. & Mar. & Nov. & Dec. \\
\hline C & 9.70 & 13.27 & 19.57 & 21.50 & 12.72 \\
\hline A & 13.58 & 9.70 & 6.13 & 11.28 & 14.60 \\
\hline $\mathrm{E}$ & 14.46 & 15.68 & 13.68 & 9.72 & 12.45 \\
\hline SE & 16.34 & 11.61 & 8.49 & 11.69 & 16.67 \\
\hline $\mathrm{W}$ & 11.37 & 15.98 & 16.42 & 8.42 & 9.25 \\
\hline $\mathrm{N}$ & 1.34 & 0 & 0 & 2.83 & 1.69 \\
\hline $\mathrm{NE}$ & 1.48 & 1.13 & 0 & 4.47 & 1.53 \\
\hline$S$ & 1.48 & 0 & 0 & 1.25 & 1.40 \\
\hline SW & 2.53 & 6.31 & 9.35 & 4.06 & 2.61 \\
\hline NW & 0 & 0 & 0 & 0 & 0 \\
\hline $\mathrm{CN}$ & 0 & 0 & 0 & 0 & 0 \\
\hline CNE & 0 & 0 & 0 & 1.44 & 0 \\
\hline CE & 0 & 0 & 0 & 1.83 & 0 \\
\hline CSE & 2.50 & 3.27 & 2.69 & 2.36 & 2.66 \\
\hline CS & 5.08 & 4.08 & 2.90 & 3.75 & 5.30 \\
\hline CSW & 0 & 0 & 0 & 0 & 0 \\
\hline CW & 0 & 1.88 & 3.60 & 1.72 & 0 \\
\hline CNW & 1.69 & 3.36 & 3.74 & 2.25 & 1.99 \\
\hline AN & 0 & 0 & 0 & 0 & 0 \\
\hline ANE & 0 & 0 & 0 & 0 & 0 \\
\hline $\mathrm{AE}$ & 0 & 0 & 0 & 1.11 & 0 \\
\hline ASE & 5.05 & 3.48 & 2.66 & 2.42 & 4.14 \\
\hline AS & 5.27 & 3.48 & 2.42 & 3.31 & 5.30 \\
\hline ASW & 0 & 0 & 0 & 0 & 0 \\
\hline AW & 0 & 0 & 0 & 0 & 0 \\
\hline ANW & 3.74 & 2.65 & 2.45 & 1.50 & 2.50 \\
\hline UD & 0 & 0 & 0 & 0 & 0 \\
\hline
\end{tabular}

own characteristics (Figure 4). Type A appears in the afternoon to night, early morning to midday less appear, and type $\mathrm{C}$ is the opposite. The rest, E-type and SE-type distribution is relatively uniform.

According to the classification of 95 persistent fog weathers, we defined the fog process according to the more appeared types associated with other types of circulation situation, then the 95 fog process can be divided into four series and 12 types. Each type of circulation background is as follows:

The first category is A-series fog. The first is the A-type fog circulation situation. The situation has a total of 11 times. The whole process of fog is type A circulation (Figure 5(a)). In this circulation conditions, most of the northern Xinjiang and even whole Xinjiang have been controlled by high-pressure, and the airport is in the anti-cyclone center or near to it.

Followed by the A-SE type fog circulation situation (Figure 5(b)). This situation 


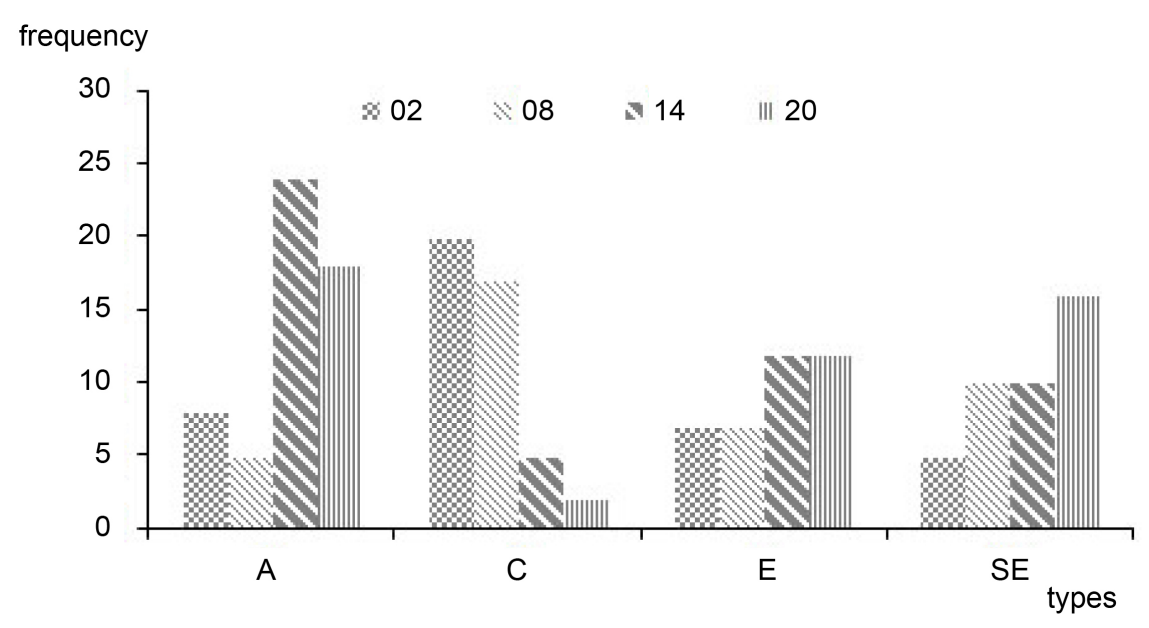

Figure 4. Daily variation regularity of circulation types.

has occurred a total of seven times. For the A-type fog, the Mongolian high pressure center east withdraw, while the degree of warp is reduced and the zonal dimension is increased. Most of the northern Xinjiang region is located on the edge of high pressure. The airport is located in the back of the high pressure. In addition to being controlled by high-pressure edges, there are southeast geostrophic wind.

Furthermore, there is an A-ASE fog circulation situation (Figure 5(c)). The situation has occurred a total of 10 times. Compared with the A-SE type, high pressure control more (Mean sea level pressure in this airport is $1035 \mathrm{hPa}$ ). Mongolian high pressure's main body moves to south, high pressure belt extends to east. There is also an A-E-type fog circulation situation (Figure 5(d)). The situation has a total of five times. High pressure's main body is obviously north, so the airport is at the bottom of the high-pressure periphery and has an eastfacing geostrophic wind.

Summed up all kinds of A-series fog type, we can see that in this series fog Xinjiang were almost all significantly controlled by high pressure, and the airport were mostly in the bottom or back bottom of the high pressure. Under normal circumstances, in about one day before the A-series fog process occurred, there is a low trough invasion of northern Xinjiang, causing a precipitation process. The water vapor is not only condensation and landing, but also to increase the overall humidity and provide better humidity conditions. Then the northern Xinjiang is controlled by the trough after the warm ridge, and the back part of the warm ridge back blow a gentle air, so there is no more obvious cold air to destroy the stability of the atmosphere, and it is conducive to the maintenance of fog.

The second category is the $\mathrm{C}$ series fog. Because during the fog atmosphere is a static structure, in the C-type the airport is not inside the cyclone, but in the relatively low pressure zone near the cyclone, that is, high and low pressure transition zone. This type of fog usually manifests as the Mongolian high pressure center east moved, high pressure west extension. Southern Xingjiang is controlled by low pressure, and the airport is in the north-high-south-low transition 
zone.

The first is the C-type fog circulation situation (Figure 6(a)). This situation has a total of five times. The whole process of fog is C-type circulation. Mongolian high pressure controls most of the northern Xinjiang. However, the northern Xinjiang is at periphery of high pressure, and the southern Xinjiang is controlled by low pressure, which is in a low pressure zone with the West Siberian
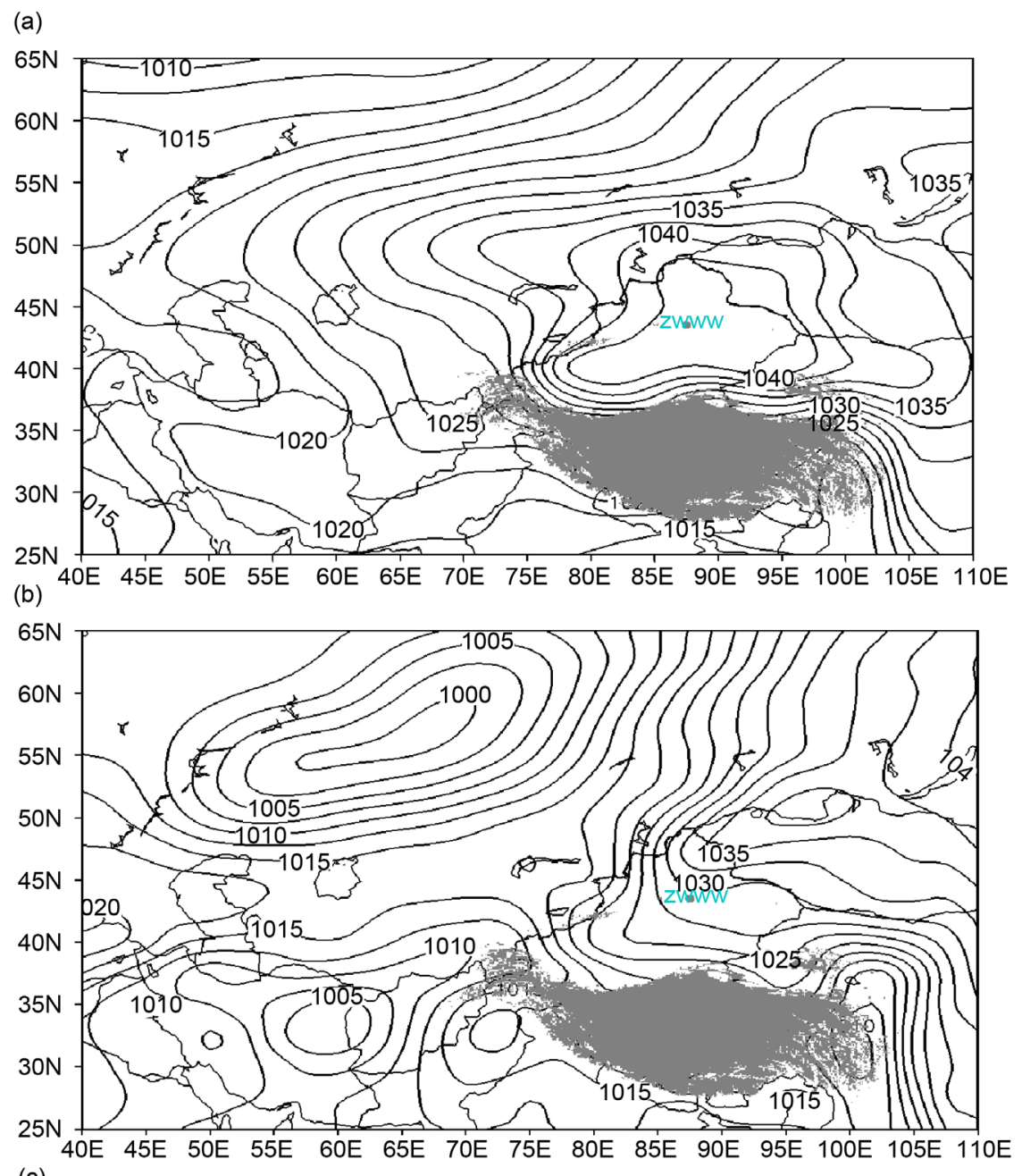
(c)

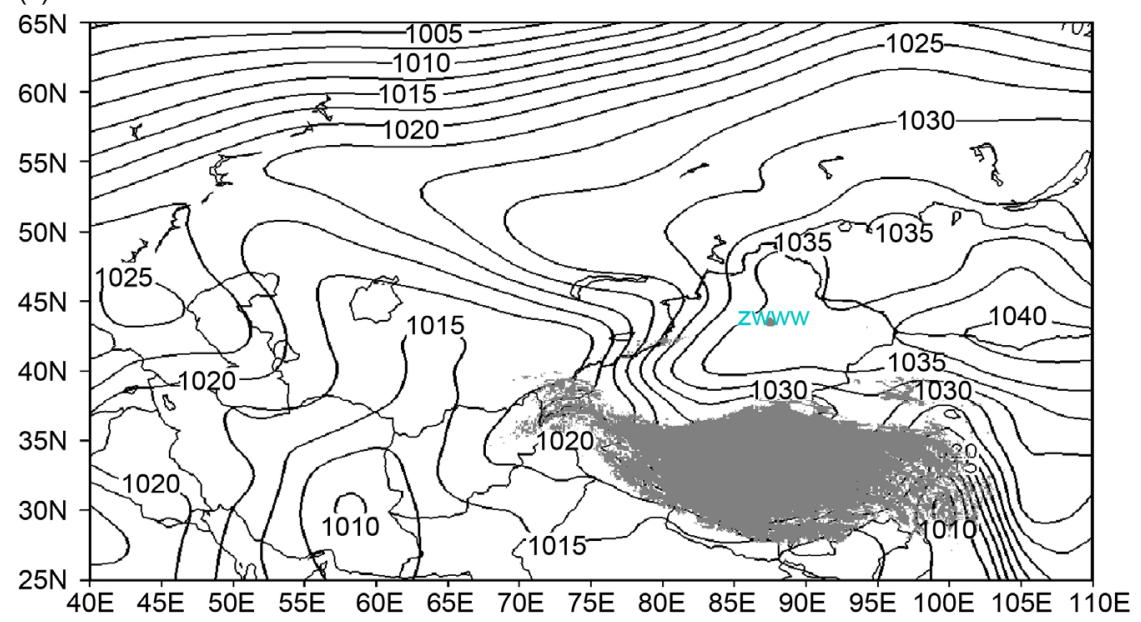




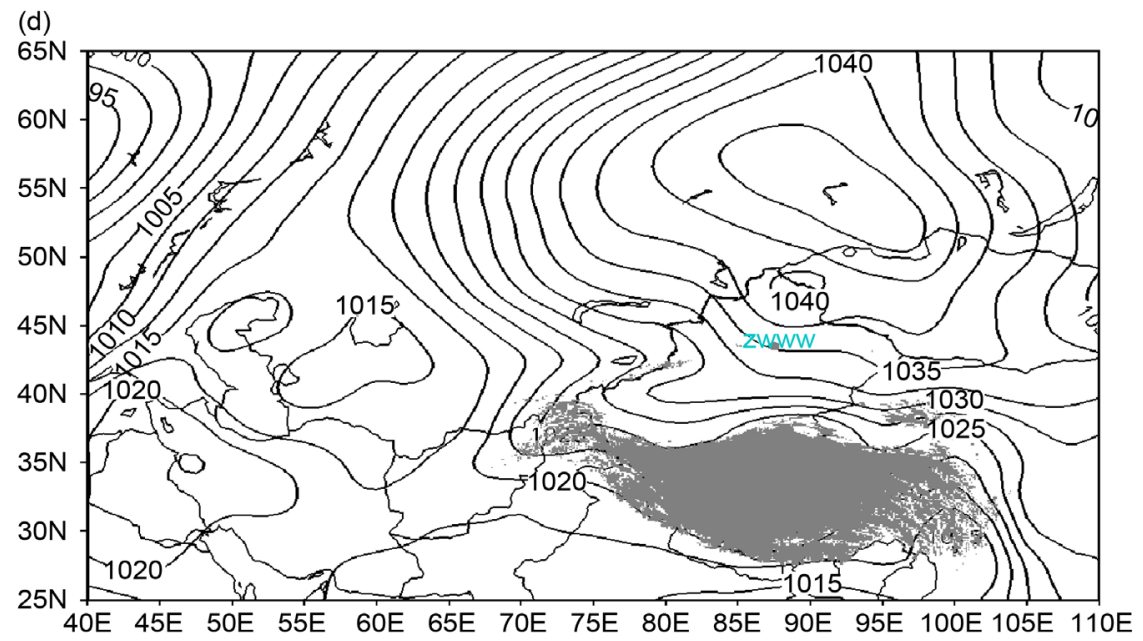

Figure 5. Sea level pressure of the circulation types A's (units: hPa): (a) A types; (b) A-SE types; (c) A-ASE types; (d) A-E types.

low pressure. Tianshan Mountains are in the high-low pressure transition zone.

To followed by is the C-SE fog circulation situation (Figure 6(b)). This situation has a total of 11 times. The southern Xinjiang lower pressure further lift to the north. To the C-type circulation situation, whole Xinjiang is in the northeast-high-southwest-low distribution. Low pressure in southern Xinjiang and West Siberia have been strengthened. The airport is on the upper edge of the north part of the low pressure. With the West Siberian low pressure further eastward, there are disturbances affecting the Tianshan Mountains, and fog weather tends to end.

C-CSE type fog circulation situation is as shown in Figure 6(c). The situation has occurred a total of 6 times. This type is similar to C-SE. High pressure is slightly east extension. The C-NE situation is different from the other three types (Figure 6(d)). The situation has occurred a total of 6 times. The north part of the northern Xinjiang is controlled by low pressure. The Northern Xinjiang Basin and Tianshan Mountains are at low pressure periphery. There is also a cyclical circulation near the airport and the airport is located at the top of the circulation, with northeast geostrophic wind.

Summarize the various types of fog in C-series, average sea level pressure in Xinjiang is basically in the northeast-high-southwest-low state, and the southern Xinjiang low pressure and West Siberia low pressure are in the same low pressure zone. Before this kind of fog emergence, the northern Xinjiang has a small amount of snow due to a cold air activity, leading to humidity increased and low temperature. This situation is conducive to the formation and maintenance of fog.

The third category is the E-series fog. Compared with the vortex-type fog, the sea level pressure gradient of the whole northern Xinjiang increases. E-series fog is divided into two kinds of situation. One is the E-SE type (Figure 7(a)). This process has a total of seven times. The average sea level pressure in northern Xinjiang is obviously high in the east and low in the west. Mongolian high pres- 
sure's position is more east and south. It split the small high pressure which is located in the northeast of northern Xinjiang. The northern Xinjiang is in the transition zone between northern Balchos Lake low pressure and Mongolian high pressure. With the Central Asian shortwave deepening and eastward, Caspian Sea high pressure strengthen and eastward, the low pressure of Lake Balkos is forced to move north and move northeast. When this high-pressure system
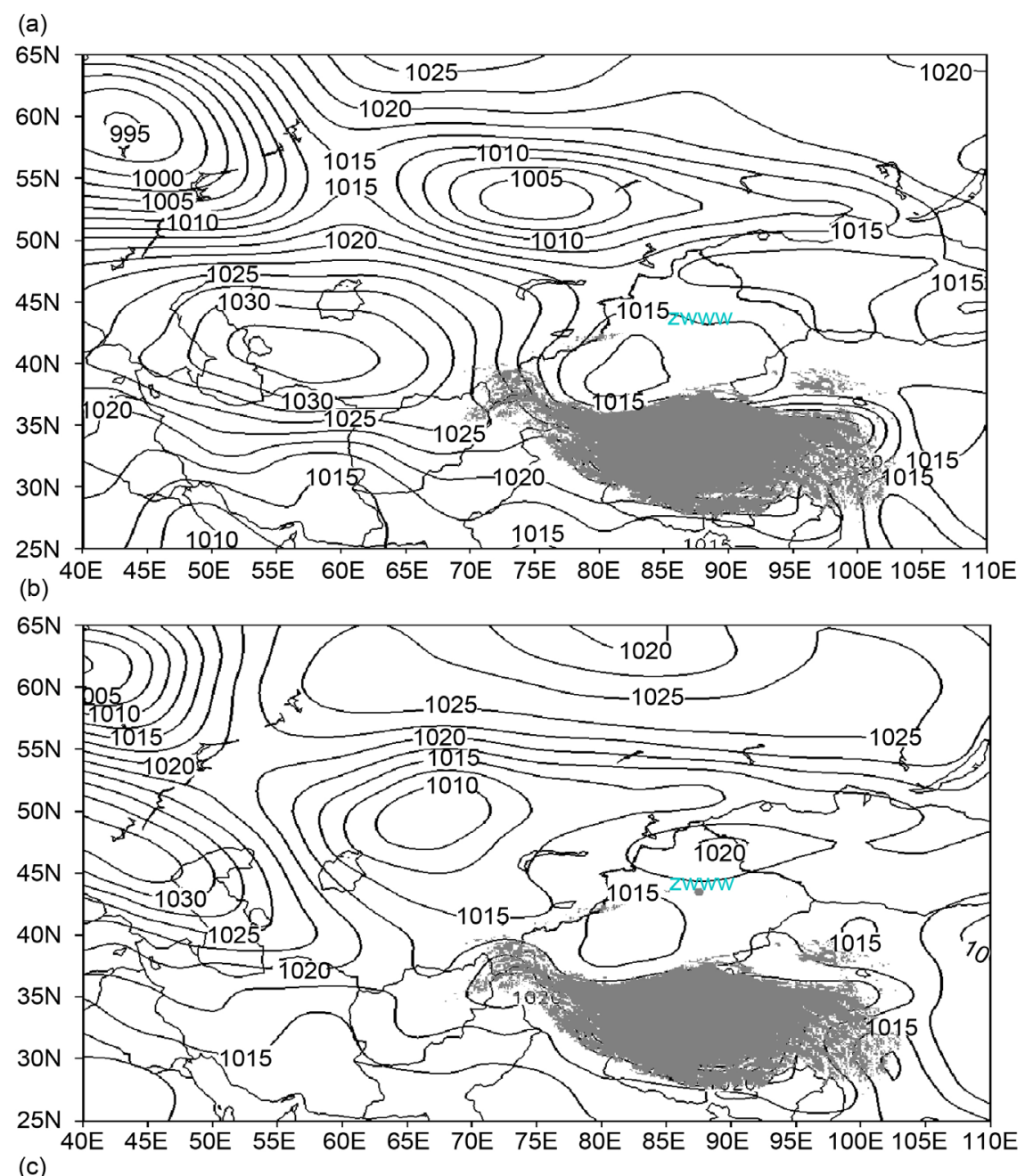
(c)

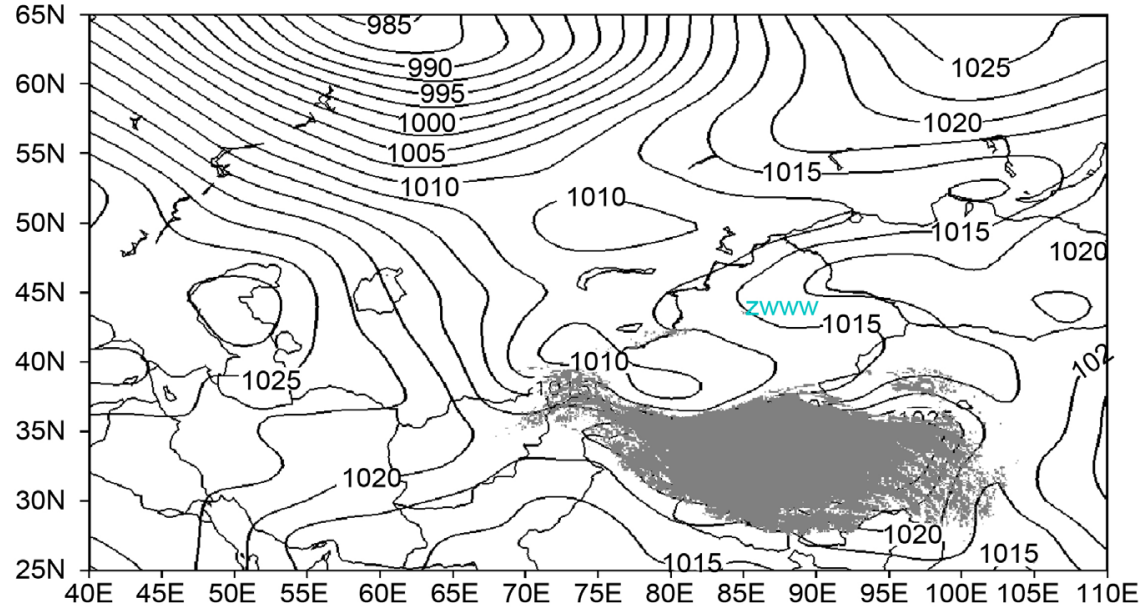




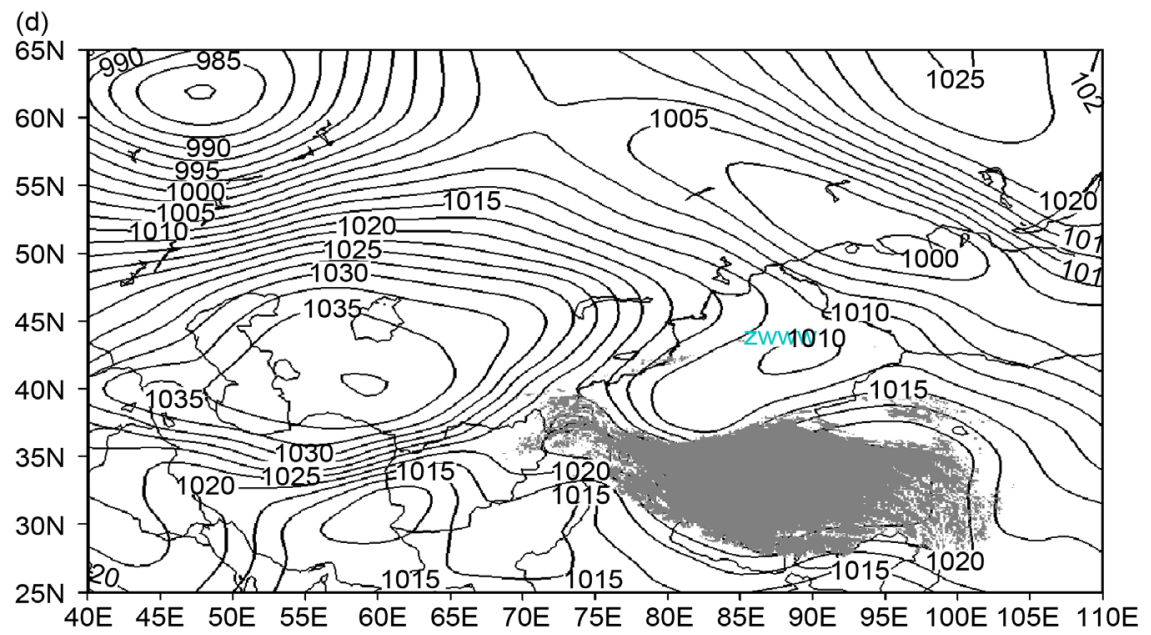

Figure 6. Sea level pressure of the circulation types C's (units: hPa): (a) C types; (b) C-SE types; (c) C-CSE types; (d) C-NE type.

(a)

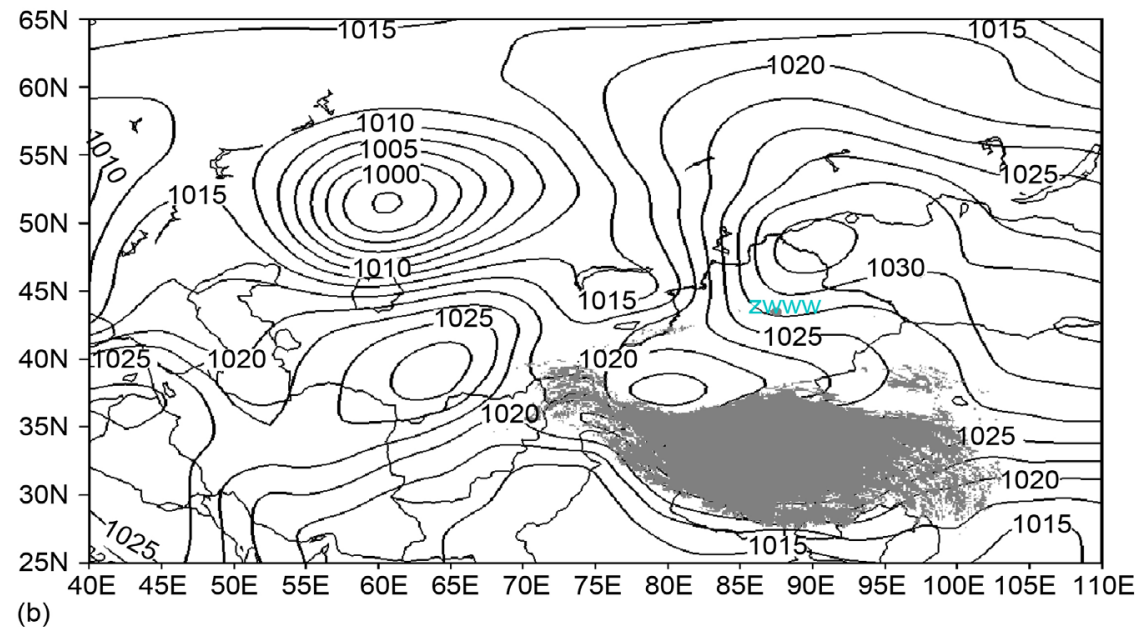
(b)

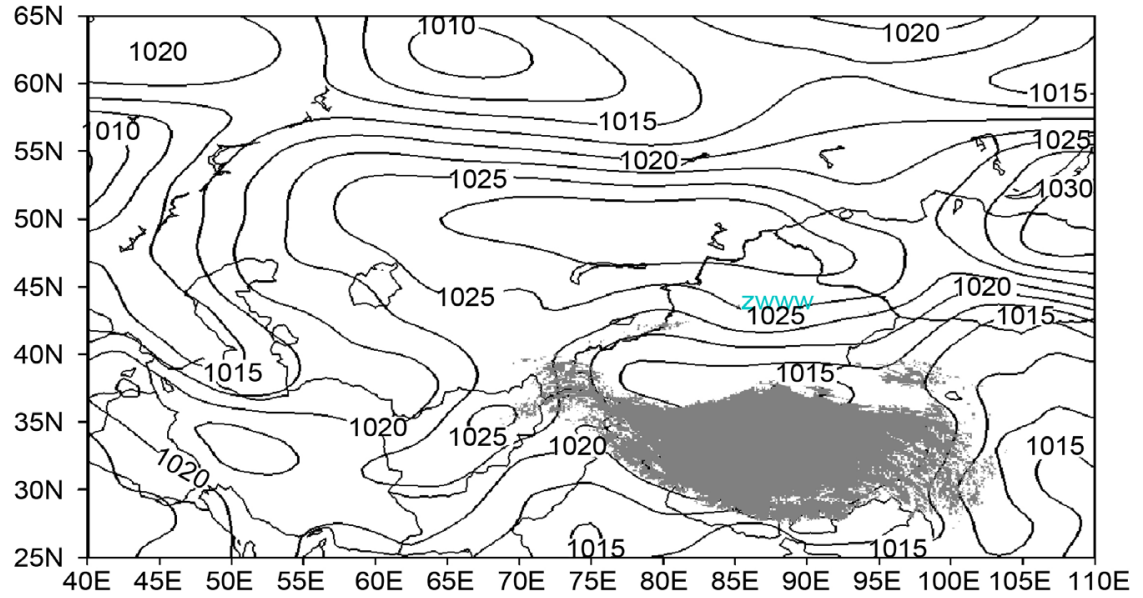

Figure 7. Sea level pressure of the circulation types E's (units: hPa): (a) E-SE types; (b) E-AE types.

carrying weak cold air invasion of northern Xinjiang, fog gradually dissipated.

The other one is the E-AE type (Figure $7(b)$ ). This process has a total of 5 
times. Most of this type of process takes place in the deep winter. Mongolian high pressure development to mature, with northward lift and west extension. The high pressure bands from east to west are formed between $45-55 \mathrm{~N}$ and show a band shape. The Northern Xinjiang is controlled by the Mongolia high pressure. There is constantly cold air back to Zhungeer basin from the cold high pressure center on the surface. Combined with cold air deposition and radiation cooling at the bottom of the basin in winter, the low level temperature drops significantly, is conducive to increase the inverse temperature difference, which is conducive to the maintenance of fog.

The third category is the SE series fog. The series fog type is divided into two kinds of situation. One circulation situation is SE-CSE (Figure 8(a)). This process occurs a total of 5 times and similar to the E-SE type, are the east-highwest-low type. The other circulation situation is SE-ASE (Figure 8(b)). This process has a total of 5 times and is similar to the E-AE type. However, for this type, high pressure center relatively goes eastward, and radial degree increases. After the cold air invasion of the northern Xinjiang, in the eastern part of northern Xinjiang, it goes to the southeast direction and become deeper. Part of the

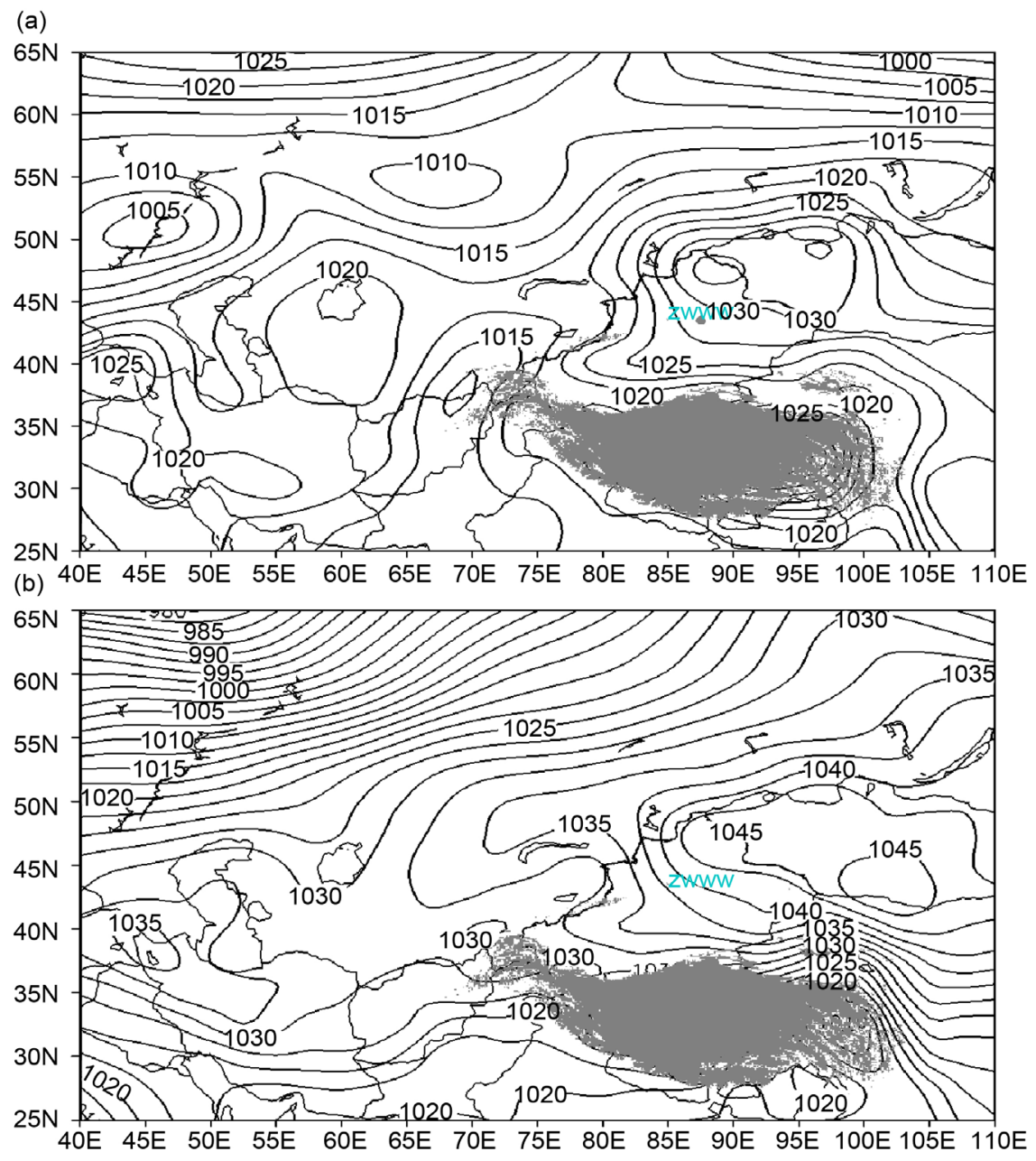

Figure 8. Sea level pressure of the circulation types SE's (units: hPa): (a) SE-CSE types; (b) SE-ASE types. 
cold air from the eastern side of the Tarim Basin goes into the southern Xinjiang. At the same time, from the central Asia to the western part of Xinjiang, there are frontal cyclone eastward, or hot trough development. Fog mainly occurs in the transition zone between the western relatively low pressure and the eastern relatively high pressure. The end of the foggy weather has a lot to do with the changes in the eastern high pressure and the activity and intensity of the next cold air. If the eastern high pressure significantly weakened eastward or there are strong cold air invasion of the northern Xinjiang, the fog weather process is over.

\section{Conclusions}

1) In recent 30 years, the airport fog was a clear upward trend, and divided into less and high incidence. Inter-monthly distribution of the main features is in November-next March. Among them, in December fog appeared most, followed by January. In mid-March the fog began to significantly reduce.

2) Based on the Lamb-Jenkinson method, the main types of fog appeared in the airport were: C (15.35\%), E (13.17\%) SE (13.0\%), W (12.24\%) and A $(11.08 \%)$, totally five types. Moreover, the inter-annual distribution of each type is not the same.

3) The type of persistent fog is mainly type A, type C, type E and type SE, in which type A mostly appears in the afternoon to night time, less in early morning-midday, and type $\mathrm{C}$ is the opposite.

4) The classification of continuous fog is divided into four series. A-series performs a strong Mongolian high pressure, all Xinjiang are controlled in high pressure. C-series is mainly for the high pressure in northern and low pressure in southern Xinjiang, the airport is in the high-low pressure transition zone. E-series and SE-series perform the "East high west low" type and high pressure belt type in the northern Xinjiang.

This paper starts from the weather situation when the fog is formed, and the L-J classification is carried out according to the weather situation when Urumqi airport fog occurs. To explore and analyze the possibility of weather situation classification objective, to improve the Urumqi fog forecast to provide a reference, so as to more accurately predict foggy weather, ahead of time to put forward preventive measures to reduce the inconvenience and loss caused by the fog.

\section{References}

[1] CAAC (2011) Civil Aviation Industry Standard of the People's Republic of China, Civil Aviation Weather, Part 1: Observation and Reporting, H / T 4016.1-2011. China Standard Press, Beijing, 2-3.

[2] Chen, L. and Gu, L. (2008) Climatic Characteristics of Fog Process in Capital Airport. Climate and Environment, 13, 783-790.

[3] Zheng, Y.-P., Li, J.-L., Liu, Z.-Q., et al. (2007) Relationship between Winter Fog and Low Temperature Inversion of Urumqi. Desert and Oasis Meteorology, 1, 21-26. 
[4] Dou, X.Y. (1996) Analysis of the Fog Weather in Urumqi. New Meteorology, 19, 15-17.

[5] Wan, Y., Cao, X., Dou, X.Y., et al. (2013) December 2011 Urumqi City, a Foggy Weather. Arid Meteorology, 31, 383-389.

[6] Li, X.-L., Chen, K.-J., Wang, K., et al. (2008) Changes and Statistical Analysis of Fog in Capital Airport. Meteorological Science and Technology, 36, 717-722.

[7] Huang, J.X., Dou, L.J. and E, L.M. (2011) Analysis and Forecast of Advection Fog Characteristics in Capital Airport. Meteorological Science and Technology, 39, 50 55.

[8] Dong, A.M. (1998) Analysis and Prediction of the Fog of Xianyang Airport. Shaanxi Meteorology, 6, 9-11.

[9] Wang, N., Yang, H.R. and Liang, Y. (2015) Nearly 37a Urumqi Airport Fog Uneven Characteristics of the Analysis. Desert and Oasis Meteorology, 9, 43-49.

[10] Lamb, H.H. (1950) Types and Spells of Weather around the Year in the British Isles. Quarterly Journal of the Royal Meteorological Society, 76, 393-438. https://doi.org/10.1002/qj.49707633005

[11] Jenkinson, A.F. and Collison, F.P. (1977) An Initial Climatology of Gales over the North Sea. Synoptic Climatology Branch Memorandum, No. 62, Meteorological Office, Bracknell.

Submit or recommend next manuscript to SCIRP and we will provide best service for you:

Accepting pre-submission inquiries through Email, Facebook, LinkedIn, Twitter, etc. A wide selection of journals (inclusive of 9 subjects, more than 200 journals)

Providing 24-hour high-quality service

User-friendly online submission system

Fair and swift peer-review system

Efficient typesetting and proofreading procedure

Display of the result of downloads and visits, as well as the number of cited articles

Maximum dissemination of your research work

Submit your manuscript at: http://papersubmission.scirp.org/

Or contact acs@scirp.org 